\title{
Imerslund-Grasbeck syndrome- a rare cause of megaloblastic anemia in an infant with homozygous mutation in CUBN gene: a case report and review of the literature
}

\author{
Mehak Agarwal $^{1}$, Sanmathi Suresh ${ }^{1}$, Dhaarani Jayaraman ${ }^{1 *}$, Sri Gayathri Shanmugam²
}

${ }^{1}$ Department of Pediatrics, ${ }^{2}$ Department of Pathology, SRIHER, Chennai, Tamil Nadu, India

Received: 24 May 2021

Accepted: 17 June 2021

*Correspondence:

Dr. Dhaarani Jayaraman,

E-mail: dhaaranij@yahoo.com

Copyright: ( $)$ the author(s), publisher and licensee Medip Academy. This is an open-access article distributed under the terms of the Creative Commons Attribution Non-Commercial License, which permits unrestricted non-commercial use, distribution, and reproduction in any medium, provided the original work is properly cited.

\begin{abstract}
Megaloblastic anaemia is one of the important causes of pancytopenia in children and nutritional deficiencies of vitamin B12 and folate are the most common causes comprising 95\% of these cases. Defects in absorption, transport and metabolism of vitamin B12 are well described, however, are very rare. We report a rare case of Imersland Grasbeck syndrome, in an infant who presented with pancytopenia, with defective absorption of B12-intrinsic factor complex at the ileum and defective tubular reabsorption of proteins in renal tubule due to same protein defect caused by mutations in two genes - CUBN (cubilin) and AMN (amnionless).
\end{abstract}

Keywords: Megaloblastic anemia, Infant, B12 deficiency, Proteiuria, pancytopenia

\section{INTRODUCTION}

Vitamin B12 and folate deficiencies are the most common causes of megaloblastic anemia (MA) in children in developing countries. Defective metabolism of these vitamins leading to MA like Imerslund Grasbeck syndrome (IGS) is very rare. It is characterized by selective vitamin B12 malabsorption with proteinuria due to defect in proteins mediating ileal absorption of B12 caused by mutations in CUBN (cubilin) and AMN (amnionless). ${ }^{1}$

We report the case of a 10 months old boy from a remote district in South India who presented with developmental delay and pancytopenia finally diagnosed with IGS due to homozygous two base pair deletion in exon 19 of the CUBN gene.

\section{CASE REPORT}

A 10-month-old boy presented with history of progressive pallor, fatiguability, poor feeding and irritability for 1 month. The child was evaluated at his hometown where investigations revealed a hemoglobin of $3.8 \mathrm{~g} / \mathrm{dl}$, total white cell count of $5.35 \times 10^{9}$ cells/L with lymphocytic predominance (Polymorph 10, lymphocytes $85 \%$ ) and platelet count of 17000/cubic.mm. Peripheral smear done showed macrocytic anemia, tear drop cells and anisopoikilocytes. Child was transfused with packed red cells in view of severe anaemia and referred to our hospital to rule out acute leukemia, in view of bicytopenia and suspicious atypical cells seen in peripheral smear.

Child was second born to third degree consanguineous couple with birthweight of $2.76 \mathrm{~kg}$. Child was immunized appropriately. He was breastfed until 6months of age and was appropriately started on complementary feeds; however, he had poor appetite and refusal of feeds for 2 months prior to presentation. Diet history of mother revealed a mixed balanced diet. Child attained ageappropriate developmental milestones until 6 months, however, he was not able to sit without support or stand 
with support, no pincer grasp was noted and only cooing was present at presentation.

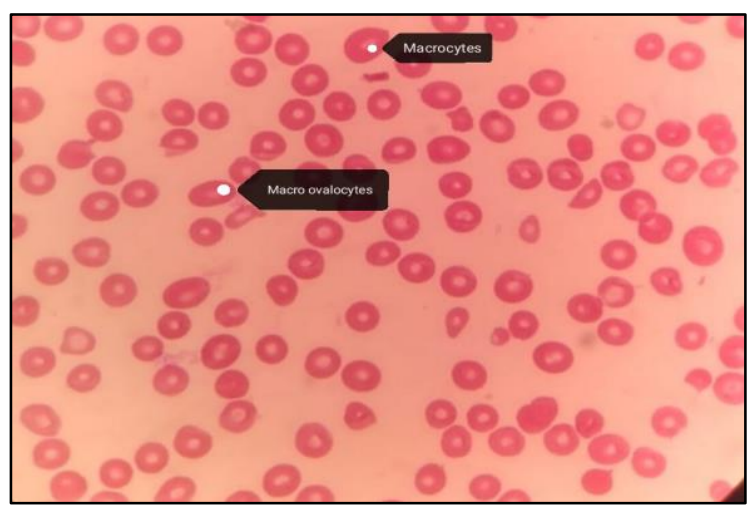

Figure 1: Peripheral smear showing macrocytic anaemia with macroovalocytes and thrombocytopenia.

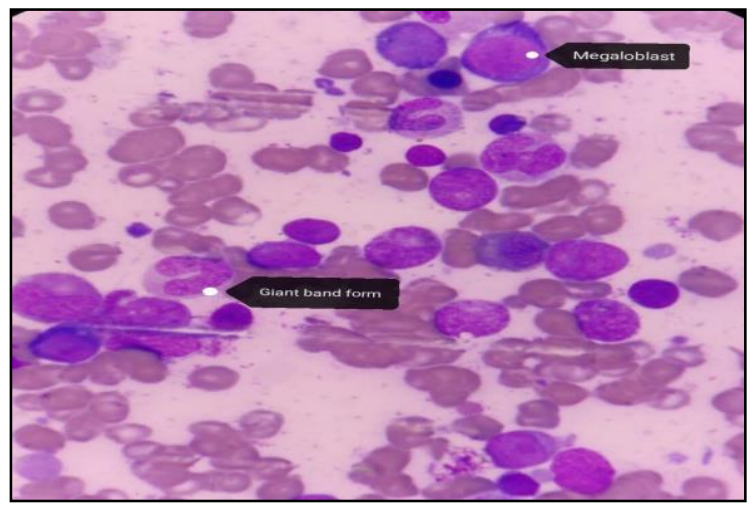

Figure 2: Bone marrow aspirate showing megaloblastic anaemia.

Child was apathetic and irritable. Anthropometry revealed malnutrition and small head (circumference at -2 Z-score). Examination showed pallor, mild frontal bossing, hyperpigmentation of knuckles, sparse hypopigmented hair, angular cheilitis, and few ecchymotic patches without any dysmorphism. On systemic examination, soft non-tender hepatomegaly was noted.

The hematological parameters showed $\mathrm{Hb}-8.7 \mathrm{~g} / \mathrm{dl}$, MCV-90 fl, platelet count-8000/cubic.mm, total WBC count-7.2 $\times 10^{9} \quad$ cells $/ \mathrm{L}$ with polymorphs 11.9 , lymphocytes 84.7, eosinophils 1 and monocytes $2 \%$. RBC count was low; Red cell distribution width was elevated (16.5). Peripheral smear showed macroovalocytes and thrombocytopenia (Figure 1). Biochemical parameters revealed mild indirect hyperbilirubinemia, elevated LDH enzyme and hypoalbuminemia; serum uric acid and electrolytes were normal. Liver and renal functions were normal. Serum vitamin B12 level was found to be very low (23 pg/ml). Reticulocyte count was $1.1 \%$ and direct Coomb's test was negative. Serum folate levels were normal.
Bone marrow biopsy revealed megaloblastoid maturation in erythroid series, hypersegmented myelocytes and absent megakaryocytes suggesting megaloblastic anemia (Figure 2). Maternal levels of B-12 were $122 \mathrm{pg} / \mathrm{ml}$ and CBC was unremarkable.

Due to absence of maternal deficiency of B-12 and hematological and neurological manifestations with profound deficiency suggest chronicity in our patient, other possibilities were considered. Urinalysis revealed nephritic range proteinuria without red cells or renal injury. Urine protein/creatinine ratio was elevated (4.5). Hence a diagnosis of IGS was made. Genetic analysis revealed a new pathological variant in the CUBN gene c.2614_2615del (p.Asp872LeufsTer3) in the exon-19 confirming the disease causing mutation.

After stabilization with transfusions, child was started on B12 therapy intramuscularly $(0.5 \mathrm{mg})$ daily for 7 days along with folic acid. He had dramatic clinical improvement; B12 therapy was continued weekly for 6 weeks followed by once a month for 6 months with a plan to continue life-long parenteral B12 supplementation bi-annually. Repeat blood count revealed increasing hemoglobin and normalization of platelet counts. Serum potassium was managed appropriately during therapy. Child is on regular follow-up for 4 months, gaining weight and catching up milestones.

\section{DISCUSSION}

Vitamin B12 deficiency results in failure of DNA replication and affects growth of rapidly replicating cells like bone marrow, gastrointestinal mucosa and skin. Causes of B12 deficiency include nutritional deficiency as the commonest cause, perrnicious anemia, tropical sprue, parasitic infestation, drugs (antiepileptics), inborn errors of metabolism like homocystenimeia and organic acidemias. Vitamin B12 deficiency in infants is often secondary to uncorrected deficiency in mother. ${ }^{2}$ Serious complications include pancytopenia and neurocognitive deficits. Mean age at presentation is 10-12 years of age. Laboratory features include moderate to severe anaemia, macrocytosis, hypersegmented neutrophils with leucopenia, thrombocytopenia, reticulocytopenia, elevated $\mathrm{LDH}$, unconjugated hyperbilirubinemia due to ineffective erythropoeisis and low serum vitamin B12 levels., ${ }^{2,3}$ Bone marrow aspiration and biopsy reveals hypercellular marrow with megaloblastic maturation and ineffective erythropoeisis.

IGS - hereditary MA with proteinuria, observed in this child is a rare disorder of defective transport of B12 in terminal ileum. Molecular basis is linked to mutations in Cubilin and Amnionless present on chromosomes 10 and 14 , respectively. The gene product is part of receptor for absorption of B12-intrinsic factor (IF) complex in the terminal ileum and mediator of protein reuptake in proximal renal tubules. . $^{3,4}$ 
IGS is a rare autosomal recessive disorder with around 300 patients reported in the literature world-wide. It is characterized by MA which responds only to parenteral vitaminB12 with onset prior to 2 years of age. However, due to its rarity and low clinical suspicion this is often diagnosed late in childhood or adulthood. ${ }^{5}$ Diagnosis is done with a high index of clinical suspicion in a young child with MA or in those who have recurrent episodes of MA with low vitaminB12 and proteinuria. Life-long supplementation with parenteral B12 is mandatory to avoid recurrence. Genetic sequencing confirms the diagnosis and parental screening is also advised.

IGS was reported in 1960 separately by Olga Imerslund and Grasbeck in Norwegian and Finnish population, respectively. It was named then as selective familial B12 malabsorption with proteinuria in those who had recurrent episodes of pancytopenia requiring transfusion and "benign" proteinuria without altered renal functions. The suspicion of B12 metabolism arose from the fact that these patients had responded earlier to treatment with liver extracts. ${ }^{6}$

Detailed study of the terminal ileal biopsy with electron microscopy including stimulated uptake of B12-IF complex by pooled gastric juice in one of his patients (14 year old boy with 2 affected and 3 normal siblings) by Mackenzie revealed no antibodies, normal structure of the mucosa and normal uptake of B12-IF complex. Hence he proposed a qualitative defect in absorption of B12-IF complex after entry into enterocytes. ${ }^{5}$

Proteinuria is a consistent finding in all these patients ranging from $1+$ to $2+$ by dipstick method and elevated protein creatinine ratio. Pathology is proposed to be an altered function of the carrier vesicles of proteins in the proximal renal tubular epithelium. Electron microscopy reveals focal proliferation of endothelial cells, mild increase in mesangial matrix and few cases with mild mesangioproliferative glomerulonephritis. ${ }^{7}$ However, the light microscopy was remarkably normal in all patients. Long term follow-up for upto 25 years revealed persistent proteinuria and no progression to renal failure in literature. $^{8}$

\section{CONCLUSION}

We emphasize the importance of early detection of IGS in any child presenting with MA in infancy due to high morbidity of this condition when not treated early and appropriately. Early genetic analysis in a child in this rare but treatable disorder is of great importance for better clinical outcome and genetic counseling.

Funding: No funding sources

Conflict of interest: None declared

Ethical approval: Not required

\section{REFERENCES}

1. Pacitto A, Prontera P, Stangoni G. ImerslundGräsbeck Syndrome in an Infant with a Novel Intronic Variant in the AMN Gene: A Case Report. Int J Mol Sci. 2019;20(3):527.

2. Rodrigues, Vera \& Dias, Alexandra \& Brito, Maria \& Galvão, Isabel \& Cordeiro-Ferreira, Gonçalo. Severe MAin an infant. BMJ case reports. 2011;10.1136.

3. Filippo G, Rendina D, Rocco V, Esposito T, Gianfrancesco F, Strazzullo P. Imerslund-Gräsbeck syndrome in a 25-month-old Italian girl caused by a homozygous mutation in AMN. Ital $\mathbf{J}$ Pediatr. 2013;39:58.

4. Birn H, Fyfe JC, Jacobsen C, Mounier F, Verroust $\mathrm{PJ}$, Orskov H, et al. Cubilin is an albumin binding protein important for renal tubular albumin reabsorption. J Clin Invest. 2000;105(10):1353-61.

5. Mackenzie IL, Donaldson RM Jr, Trier JS, Mathan VI. Ileal mucosa in familial selective vitamin B 12 malabsorption. N Engl J Med. 1972; 286(19):10215 .

6. Grasbeck R, Gordin R, Kantero I, Kuhlback B. Selective vitamin B12 malabsorption and proteinuria in young people. A syndrome. Acta Med Scand. 1960;167:289-96.

7. Liang DC, Hsu HC, Huang FY, Wei KN. Imerslund-Gräsbeck syndrome in two brothers: renal biopsy and ultrastructural findings. Pediatr Hematol Oncol. 1991;8(4):361-5.

8. Ercan Z, Demir ME, Ulas T, Ingec M, Horoz M. A long-term follow-up of an Imerslund-Grasbeck syndrome patient with proteinuria. Nefrologia. 2013; 33(1):147-8.

Cite this article as: Agarwal M, Suresh S, Jayaraman D, Shanmugam SG. Imerslund-Grasbeck syndrome- a rare cause of megaloblastic anemia in an infant with homozygous mutation in CUBN gene: a case report and review of the literature. Int J Contemp Pediatr 2021;8:1281-3. 